\title{
The Cost of Crisis in Clinical Psychological Science
}

\author{
Joshua B. Grubbs ${ }^{1}$
}

A commentary on:

Yarkoni T. (2020). The generalizability crisis. The Behavioral and brain sciences, 1-37. Advance online publication. https://doi.org/10.1017/S0140525X20001685

Yarkoni has argued that psychology is facing a generalizability crisis, but the real cost of this crisis is obscured by a focus on topics from psychology's most academic subfields. Psychology is also filled with applied subfields, and it is within those subfields-especially clinical science-where the cost of a generalizability crisis will be most severe.

The past decade has clearly demonstrated that psychology is replete with contradictory, redundant, and irreplicable findings. Ego depletion exists (Baumeister \& Vohs, 2007), except when it doesn't (Hagger et al., 2016), or when it's too small to have a meaningful effect (Dang et al., 2021). Depending on which psychologist is writing the paper, people may alternatively have grit (Duckworth \& Quinn, 2009), be resilient (Friborg et al., 2005), or just demonstrate specific aspects of conscientiousness (Schmidt et al., 2018). To an objective observer, it may seem that largeswaths of psychology have long moved past Feynman's (1974) warnings of a cargo cult science and all-butabandoned the science part altogether. As more psychologists have publicly acknowledged that huge portions of our science are merely either the selling of old wine in new bottles or attempts to sell bottled water by calling it wine, the past decade in psychological science has been a crisis of crises. The replication crisis has given way to a measurement crisis (Flake \& Fried, 2020), a validity crisis (Clark \& Watson, 2019; Flake et al., 2017; Lundh, 2019), a practicality crisis (Berkman \& Wilson, 2021), and a litany of others (Hughes, 2018). To this burgeoning but rich legacy of crises, Yarkoni has added another: The generalizability crisis.

Yarkoni has argued that psychology has fallen into what Meehl (1990) warned of, having created a field of scientists whose entire careers are devoted to describing, demonstrating, and marketing nothing. This, in turn, wastes resources such as time, effort, and funds, as all are being spent on experimental studies that have no chance of actually answering the question they purport to answer. Perhaps more concerningly, this crisis points to a loss of credibility for the entire field. Indeed, these costs are high. Yet, for some domains within psychology, a crisis of generalizability may come at a greater cost than wasted resources or statistical charades.

For seminal work in verbal overshadowing to fall short of basic generalizability is disappointing, particularly given the efforts invested in multi-site replication efforts. Even so, would anyone argue that social costs of these efforts extend much further beyond the loss of those resources? Similarly, the three-decade-long-andstill-continuing obsession with ego depletion has undoubtedly done more to deplete financial and human capital resources than demonstrate any generalizable claim about willpower or self-control (Friese et al., 2019). Yet, the societal costs of those Sisyphean attempts are likely relatively low. Failed experiments certainly may have derailed careers, and such losses should not be ignored. Even so, the average layperson will be more influenced by the ice-cream they choose to eat for dessert today than they will by failure of ego-depletion to deliver on its years of bold claims. Could the same be said for interventions in clinical psychology? If evidence-based treatments and "gold standard" therapies for depression, post-traumatic stress, or anorexia lack generalizability, are the costs accurately measured in wasted scientific resources?

Even though all applied scientists in psychology should be deeply concerned about the cost of a generalizability crisis, clinical science should be so in even greater measure. It is no accident that Meehl's perennially salient concerns about the quality and rigor of

\footnotetext{
${ }^{1}$ Bowling Green State University Department of Psychology, 822 E Merry Ave, Bowling Green, OH 43403; GrubbsJ@BGSU.edu; www.JoshuaGrubbsPhD.com
} 
psychological science were born of a career that integrated clinical practice (Meehl, 1987). The costs of ungeneralizable and sloppy science are higher when that science is guiding practitioners' decisions. There is abundant evidence that many of clinical psychology's gold-standard treatments are built on statistical errors, questionable research practices, and bad inferences (Sakaluk et al., 2019). If even a few of the remaining treatments that are not built on gross statistical errors or questionable research practices are found to lack generalizability $-\mathrm{a}$ critique that practicing clinicians have voiced for many years (Lilienfeld et al., 2013; Stewart et al., 2012)-what then remains of the field?

Undoubtedly, the same criticisms and concerns that I have framed around clinical psychology might also apply to other applied domains. Educational psychology has influenced real world decisions for years, and the work done in industrial and organizational psychology has affected careers of countless individuals. Similarly, there are social and cognitive psychologists that are heavily engaged in applied research that bears real world implications for both individual people and broader policy. Such fields and scientists should be similarly shaken by the notion that their work fundamentally does not and cannot actually statistically evaluate the questions they claim to be evaluating. If the generalizability crisis does indeed come to the forefront-if enough people do as Yarkoni has suggested and stop honoring the charade of statistical inference-none of the major subfields of psychology will be safe. Even so, the costs for clinical psychology should and will be steep.

All of psychology claims to do impactful science. Yet, clinical psychology's perennial claims of alleviating suffering and literally saving lives are unique among the subfields of our science. The logical upshot of such claims is that the costs of a generalizability crisis are measured in human lives, not wasted resources. Yarkoni closes by offering readers a choice. The first option is the choice to improve, to make more reasonable inferences, temper one's claims, and return to more basic forms of research such as descriptive and qualitative analyses. The second is to simply stick one's head in the sand and recommit to the cargo cult rituals that have brought success to so many for so long. Although the latter of these two options is certainly the easier path, for psychological scientists in applied domains, particularly those in clinical science, the human costs of ignoring such a crisis must leave them with only one choice.

\section{Conflict of Interest}

The author declares no conflict of interest in writing this commentary. The author declares no specific funding for this work.

\section{References}

Baumeister, R. F., \& Vohs, K. D. (2007). Self-Regulation, Ego Depletion, and Motivation. Social and Personality Psychology Compass, 1(1), 115-128. https://doi.org/10.1111/j.1751-9004.2007.00001.x

Berkman, E. T., \& Wilson, S. M. (2021). So Useful as a Good Theory? The Practicality Crisis in (Social) Psychological Theory. Perspectives on Psychological Science, 1745691620969650. https://doi.org/10.1177/1745691620969650

Clark, L. A., \& Watson, D. (2019). Constructing validity: New developments in creating objective measuring instruments. Psychological Assessment. https://doi.org/10.1037/pas0000626

Dang, J., Barker, P., Baumert, A., Bentvelzen, M., Berkman, E., Buchholz, N., Buczny, J., Chen, Z., De Cristofaro, V., de Vries, L., Dewitte, S., Giacomantonio, M., Gong, R., Homan, M., Imhoff, R., Ismail, I., Jia, L., Kubiak, T., Lange, F., ... Zinkernagel, A. (2021). A Multilab Replication of the Ego Depletion Effect. Social Psychological and Personality Science, 12(1), 14-24. https://doi.org/10.1177/1948550619887702

Duckworth, A. L., \& Quinn, P. D. (2009). Development and Validation of the Short Grit Scale (Grit-S). Journal of Personality Assessment, 91(2), 166-174. https://doi.org/10.1080/00223890802634290

Feynman, R. P. (1974). Cargo cult science. Engineering and Science, 37(7), 10-13.

Flake, J. K., \& Fried, E. I. (2020). Measurement Schmeasurement: Questionable Measurement Practices and How to Avoid Them. Advances in Methods and Practices in Psychological Science, 3(4), 456-465. https://doi.org/10.1177/2515245920952393

Flake, J. K., Pek, J., \& Hehman, E. (2017). Construct Validation in Social and Personality Research: Current Practice and Recommendations. Social Psychological and Personality Science, 8(4), 370-378. https://doi.org/10.1177/1948550617693063

Friborg, O., Barlaug, D., Martinussen, M., Rosenvinge, J. H., \& Hjemdal, O. (2005). Resilience in relation to 
personality and intelligence. International Journal of Methods in Psychiatric Research, 14(1), 29-42. https://doi.org/10.1002/mpr.15

Friese, M., Loschelder, D. D., Gieseler, K., Frankenbach, J., \& Inzlicht, M. (2019). Is Ego Depletion Real? An Analysis of Arguments. Personality and Social Psychology Review, 23(2), 107-131. https://doi.org/10.1177/1088868318762183

Hagger, M. S., Chatzisarantis, N. L. D., Alberts, H., Anggono, C. O., Batailler, C., Birt, A. R., Brand, R., Brandt, M. J., Brewer, G., Bruyneel, S., Calvillo, D. P., Campbell, W. K., Cannon, P. R., Carlucci, M., Carruth, N. P., Cheung, T., Crowell, A., De Ridder, D. T. D., Dewitte, S., ... Zwienenberg, M. (2016). A Multilab Preregistered Replication of the Ego-Depletion Effect. Perspectives on Psychological Science, 11(4), 546-573. https://doi.org/10.1177/1745691616652873

Hughes, B. M. (2018). Psychology in Crisis. Macmillan International Higher Education.

Lilienfeld, S. O., Ritschel, L. A., Lynn, S. J., Cautin, R. L., \& Latzman, R. D. (2013). Why many clinical psychologists are resistant to evidence-based practice: Root causes and constructive remedies. Clinical Psychology Review, 33(7), 883-900. https://doi.org/10.1016/j.cpr.2012.09.008

Lundh, L.-G. (2019). The Crisis in Psychological Science and the Need for a Person-Oriented Approach. In J. Valsiner (Ed.), Social Philosophy of Science for the Social Sciences (pp. 203-223). Springer International Publishing. https://doi.org/10.1007/978-3-030-33099-6_12

Meehl, P. E. (1987). Theory and practice: Reflections of an academic clinician. In Standards and evaluation in the education and training of professional psychologists: Knowledge, attitudes, and skills (pp. 723). Transcript Press.

Meehl, P. E. (1990). Why Summaries of Research on Psychological Theories are Often Uninterpretable. Psychological Reports, 66(1), 195-244. https://doi.org/10.2466/pr0.1990.66.1.195

Sakaluk, J. K., Williams, A. J., Kilshaw, R. E., \& Rhyner, K. T. (2019). Evaluating the evidential value of empirically supported psychological treatments (ESTs): A meta-scientific review. Journal of Abnormal Psychology, 128(6), 500-509. https://doi.org/10.1037/abn0000421

Schmidt, F. T. C., Nagy, G., Fleckenstein, J., Möller, J., \& Retelsdorf, J. (2018). Same Same, but Different? Relations between Facets of Conscientiousness and Grit. European Journal of Personality, 32(6), 705-720. https://doi.org/10.1002/per.2171
Stewart, R. E., Stirman, S. W., \& Chambless, D. L. (2012). A qualitative investigation of practicing psychologists' attitudes toward research-informed practice: Implications for dissemination strategies. Professional Psychology: Research and Practice, 43(2), 100-109. https://doi.org/10.1037/a0025694 